\title{
Inhibition of Steroid-induced Prostatic Hyperplasia in Rats by Treatment with Anti-Androgen (TZP-4238)
}

\author{
Masanori MURAKOSHI, Masashi TAGAWA, RiE INADA, \\ Minoru SUZUKI, ATsushi MIZOKAMI*, AND KeIICHI WATANABE** \\ Safety Research Department, Teikoku Hormone Mfg. Co. Ltd., \\ Kawasaki 213, *Department of Molecular Cell Biology, University \\ of Occupational and Environment Health, Kitakyusyu 807, and \\ **Department of Pathology, Tokai University, School of Medicine, \\ Kanagawa 259-11, Japan
}

\begin{abstract}
The effect of a synthetic steroidal anti-androgen, TZP-4238, on steroid-induced rat prostatic hyperplasia was investigated. Male Wistar rats were divided into four experimental groups. Group 1 consisted of intact controls. The other animals were castrated. The castrated animals were treated for 7 weeks with 1) testosterone $1 \mathrm{mg} /$ head plus $17 \beta$-estradiol $\left(\mathrm{E}_{2}\right) 0.01 \mathrm{mg} /$ head (Group 2), 2) testosterone plus $E_{2}+$ TZP-4238 $8 \mathrm{mg} / \mathrm{kg}$ (Group 3) and 3) testosterone plus $\mathrm{E}_{2}+$ chlormadinone acetate (CMA) 20 $\mathrm{mg} / \mathrm{kg}$ (Group 4). TZP-4238 and CMA were administered orally for 4 weeks after 3 weeks treatment with testosterone plus $\mathrm{E}_{2}$. In group 2, glandular hyperplasia of the prostate was clearly observed, and the number of bromo-deoxyuridine (BrdU)-positive cells showed a significant increase. In contrast, combined treatment with TZP-4238 (Group 3) or CMA (Group 4) produced marked atrophy of the glandular epithelium, and the number of BrdU-positive cells were remarkably decreased compared with Group 2. In addition, the localization of glutathione-peroxidase (GSH-PO) which effectively reduces the lipid peroxides in the glandular epithelial cells was markedly decreased. Furthermore, nuclear immunostaining of androgen receptor was remarkably decreased after combined treatment with TZP-4238 or CMA. Our data indicate that TZP-4238 is a potent steroidal androgen receptor antagonist for the prevention of rat prostatic growth in the steroid-induced prostatic hyperplasia model.
\end{abstract}

Key words: Anti-androgen, TZP-4238, Chlormadinone acetate, Prostatic hyperplasia, Rat.

(Endocrine Journal 40: 479-488, 1993)

IN A PREVIOUS report [1], it was shown that glandular hyperplasia of the prostate developed in castrated dogs after combined treatment with $5 \alpha$-androstane- $3 \alpha, 17 \beta$-diol and $17 \beta$-estradiol $\left(\mathrm{E}_{2}\right)$. It is generally accepted that estrogens play a critical role in the etiology of canine and human benign prostatic hyperplasia (BPH) [2-5].

Previous studies using castrated steroid-treated dogs have indicated that $17 \alpha$-acetoxy-6-chloro-2oxa-4,6-pregnadiene-3,20-dione (TZP-4238), a

Received: February 3, 1993

Accepted: May 21, 1993

Correspond to: Dr. Masanori MURAKOSHI, Safety Research Department, Teikoku Hormone Mfg. Co. Ltd., 1604 Shimosakunobe, Takatsu-ku, Kawasaki 213, Japan new type of steroidal anti-androgen, inhibits the experimental induction of $\mathrm{BPH}$ [1]. Furthermore, we have found that the dose of TZP-4238 required to inhibit the development of glandular hyperplasia is lower than that of chlormadinone acetate (CMA) [1]. Therefore, we postulated that TZP4238 was more potent than CMA in preventing steroid-induced canine prostatic hyperplasia [1].

The purpose of the present study was to further examine the effect of TZP-4238 on rat prostatic hyperplasia model after combined treatment with testosterone and $\mathrm{E}_{2}$. In addition, an analytical examination for cell proliferation activity, using 5-bromo-deoxyuridine (BrdU)-positive cell ratio and an attempt to observe immunocytochemical 
localization of androgen receptor (AR) and glutathione-peroxidase (GSH-PO), which effectively reduces the lipid peroxides, were also investigated.

\section{Materials and Methods}

\section{Experiments}

Male Wistar rats weighing 200 to $250 \mathrm{~g}$ were used. The details of treatment are given in Fig. 1. Five animals served as controls (Group 1). The other animals were castrated and allowed two days for involution of the prostate before any hormonal treatment was begun. After this period, castrated animals were treated for 7 weeks with 1) testosterone (Sigma Chemical Co., St. Louis, MO) 1 $\mathrm{mg} /$ head plus $17 \beta$-estradiol $\left(\mathrm{E}_{2}\right.$; Teikoku Hormone, Mfg. Co. Ltd., Kawasaki) $0.01 \mathrm{mg} / \mathrm{head}$ (Group 2, $\mathrm{n}=5$ ), 2) testosterone plus $\mathrm{E}_{2}$ and TZP-4238 $8 \mathrm{mg} / \mathrm{kg}$ (Group 3, $\mathrm{n}=5$ ) and 3) testosterone plus $\mathrm{E}_{2}$ and CMA $20 \mathrm{mg} / \mathrm{kg}$ (Group 4, n = 5). Testosterone and $\mathrm{E}_{2}$ were dissolved in dimethylsulfoxide and were administered subcutaneously six times per week. TZP-4238 and CMA were suspended in $2 \%$ Tween 80 and were administered orally (six times per week) for 4 weeks after 3 weeks treatment with testosterone + $\mathrm{E}_{2}$.

One hour prior to sacrifice, animals were given an intraperitoneal injection of 5-bromo-2deoxyuridine (BrdU; Sigma Chemical Co., St. Louis, MO), at a dose of $100 \mathrm{mg} / \mathrm{kg}$ body weight. Each rat was killed by decapitation and the ventral prostate was removed.
Organ weight

The weight of the prostates were recorded (absolute weight). Weights relative to body weight (relative weight) were calculated.

\section{Histopathological examination}

The prostates were fixed in $0.1 \mathrm{M}$ phosphate-buffered $10 \%$ formalin and embedded in paraffin, mounted and stained with hematoxylin and eosin.

\section{Immunohistochemical staining}

\section{1) $\operatorname{BrdU}$}

Formalin fixed and paraffin sections were used. Sections $(4 \mu \mathrm{m})$ were cut, deparaffinized with xylene and rinsed thoroughly with ethanol. The sections were then placed in absolute methanol containing $0.3 \%$ hydrogen peroxide for $30 \mathrm{~min}$ at room temperature in inactivate endogenous peroxidase activity. Sections were washed twice in 0.01 $\mathrm{M}$ phosphate-buffered saline (PBS), $\mathrm{pH} 7.4,5 \mathrm{~min}$ per wash. Thereafter, sections were immersed in $2 \mathrm{~N} \mathrm{HCl}$ at $25^{\circ} \mathrm{C}$ for $20 \mathrm{~min}$ to denature the DNA. To neutralize the $\mathrm{HCl}$, the sections were rinsed in $0.1 \mathrm{M}$ borate buffer, $\mathrm{pH}$ 7.6. After washing in 0.01 M PBS, the sections were blocked with $5 \%$ normal goat serum for $30 \mathrm{~min}$, then incubated for $2 \mathrm{~h}$ with 1:50 mouse monoclonal anti-BrdU antibody (Becton Dickinson Immunocytometry Systems, San Jose, CA). After washing in $0.01 \mathrm{M}$ PBS, the sections were covered with biotin-conjugated goat anti-mouse IgG for $1 \mathrm{~h}$, washed and then incu-

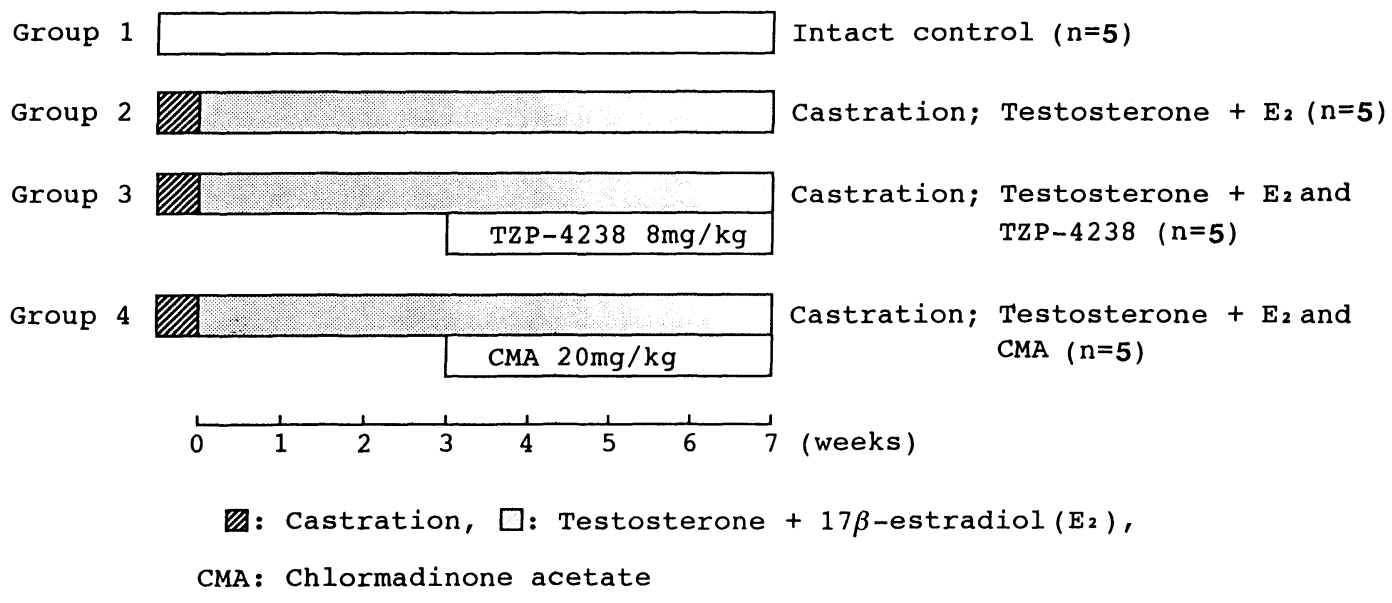

Fig. 1. Experimental schedule. 
bated with streptavidin-biotin complex (Histofine SAB-PO (M) kit, Nichirei, Tokyo) for $1 \mathrm{~h}$. After washing in $0.01 \mathrm{M}$ PBS, the sections were incubated in Graham-Karnovsky's reaction medium [6] which contained 3,3'-diaminobenzidine-tetrahydrochloride (DAB, Wako Pure Chemical Industries, Osaka) and $0.005 \%$ hydrogen peroxide in $0.05 \mathrm{M}$ Tris- $\mathrm{HCl}$ buffer, $\mathrm{pH} 7.6$, for 5 to $10 \mathrm{~min}$ at room temperature. Then the sections were counterstained for nuclei with hematoxylin. As an immunologically negative control, 1:50 diluted nonimmune mouse serum was used. In addition, the BrdU-positive cell ratio (\%) was calculated as the positive cell number in one acinus/total cell number in the acinus $\times 100$.

\section{2) $G S H-P O$}

The prostates were fixed in periodate-lysine- $4 \%$ paraformaldehyde solution (4\% PLP) [7] for $6 \mathrm{~h}$ at $4^{\circ} \mathrm{C}$ under constant agitation. The fixed tissues were then washed in $0.01 \mathrm{M}$ PBS, $\mathrm{pH} 7.4$, containing sucrose from 10 to eventually $20 \%$ overnight at $4^{\circ} \mathrm{C}$. Subsequently, $6 \mu \mathrm{m}$ frozen sections were prepared from the washed tissues in a cryostat, and were placed on albumin-coated glass slides. The sections were washed in $0.01 \mathrm{M}$ PBS, pH 7.4, and then were stained by Nakane's direct peroxidase-labeled antibody method with anti-GSH-PO IgG Fab fragment [8]. For light microscopic observations of GSH-PO, $6 \mu \mathrm{m}$ frozen sections were incubated with the antibody labeled with horseradish peroxidase (Sigma Chemical Co., St. Louis, MO) for $1 \mathrm{~h}$. After the incubation was completed, the immuno-peroxidase staining was performed as described above.

\section{3) $A R$}

Fresh prostate were frozen in dry-ice cooled ethanol. Six $\mu \mathrm{m}$ thickness of frozen sections were prepared in a cryostat and attached to albumincoated glass slides. The sections were fixed for 10 min at $4^{\circ} \mathrm{C}$ in Zamboni's fixative [9]. After washing with 0.01 M PBS containing $20 \%$ sucrose, the sections were soaked in absolute methanol containing $0.3 \%$ hydrogen peroxide for $30 \mathrm{~min}$ at room temperature in inactivate endogenous peroxidase activity. After washing in $0.01 \mathrm{M}$ PBS, the sections were incubated overnight at $4^{\circ} \mathrm{C}$ with $\mathrm{NH} 27$, a rabbit polyclonal anti-AR antibody (1:1000) [10]. After washing in $0.01 \mathrm{M}$ PBS, the sections were covered with biotin-conjugated goat anti-rabbit IgG for $1 \mathrm{~h}$, washed and then incubated with streptavidin-biotin complex (Histofine SAB-PO (R) Kit, Nichirei, Tokyo) for $1 \mathrm{~h}$. After washing in $0.01 \mathrm{M}$ PBS, the immuno-peroxidase staining was performed as described above.

\section{Results}

\section{Prostatic weights}

The prostatic weights are shown in Table 1 . Statistically significant increases were noted in the absolute and relative weights of prostate treated with testosterone plus $\mathrm{E}_{2}$ to the castrated rats (Group 2). The administration of testosterone plus $\mathrm{E}_{2}$ and TZP-4238 (Group 3) or CMA (Group 4) to the castrated rats marked a reduction in the absolute and relative weights or prostates. These values were similar to those for the intact control (Group 1).

\section{Histopathological and immunohistochemical findings Group 1 (Intact control)}

The glandular epithelial cells appeared as single-layered, cylindrical cells. The cytoplasm of the

Table 1. Effect of TZP-4238 or CMA on prostatic weight and BrdU-positive cell ratio

\begin{tabular}{cllllll}
\hline & & & \multicolumn{2}{c}{ Prostatic weight (mg) } & \\
\cline { 4 - 5 } Group Preparation & $\mathrm{n}$ & Treatment & Absolute & Relative & & $\begin{array}{l}\text { BrdU-positive } \\
\text { cell ratio (\%) }\end{array}$ \\
\hline 1 & Intact control & 5 & - & $604 \pm 129.9$ & $175 \pm 46.5$ & $0.72 \pm 0.28$ \\
2 & Castrated & 5 & $\mathrm{~T}+\mathrm{E}_{2}$ & $857 \pm 106.4^{*}$ & $295 \pm 48.6^{* *}$ & $5.49 \pm 0.57^{* *}$ \\
3 & Castrated & 5 & $\mathrm{~T}+\mathrm{E}_{2}+\mathrm{TZP}-4238$ & $427 \pm 55.6$ & $128 \pm 16.3$ & $0.58 \pm 0.20$ \\
4 & Castrated & 5 & $\mathrm{~T}+\mathrm{E}_{2}+\mathrm{CMA}$ & $544 \pm 45.5$ & $169 \pm 8.3$ & $0.88 \pm 0.40$ \\
\hline
\end{tabular}

Values are the mean $\pm \mathrm{SD} . \mathrm{T}$, Testosterone; $\mathrm{E}_{2}, 17 \beta$-estradiol; CMA, Chlormadinone acetate; BrdU, Bromodeoxyuridine. *, $P<0.05$ vs. intact control (Dunnett's multiple comparison test). ${ }^{* *}, P<0.01$ vs. intact control (Dunnett's multiple comparison test). 


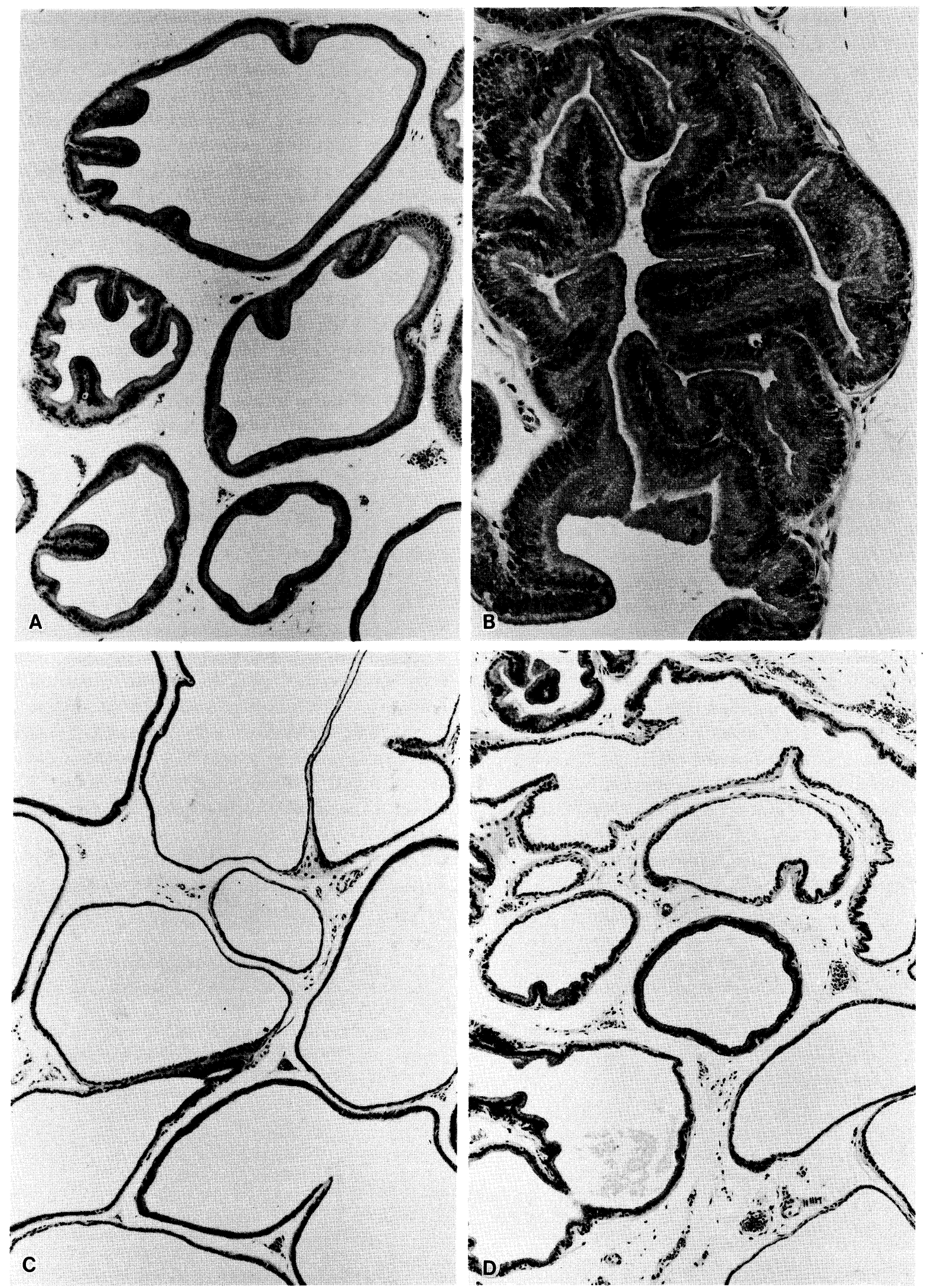

Fig. 2 


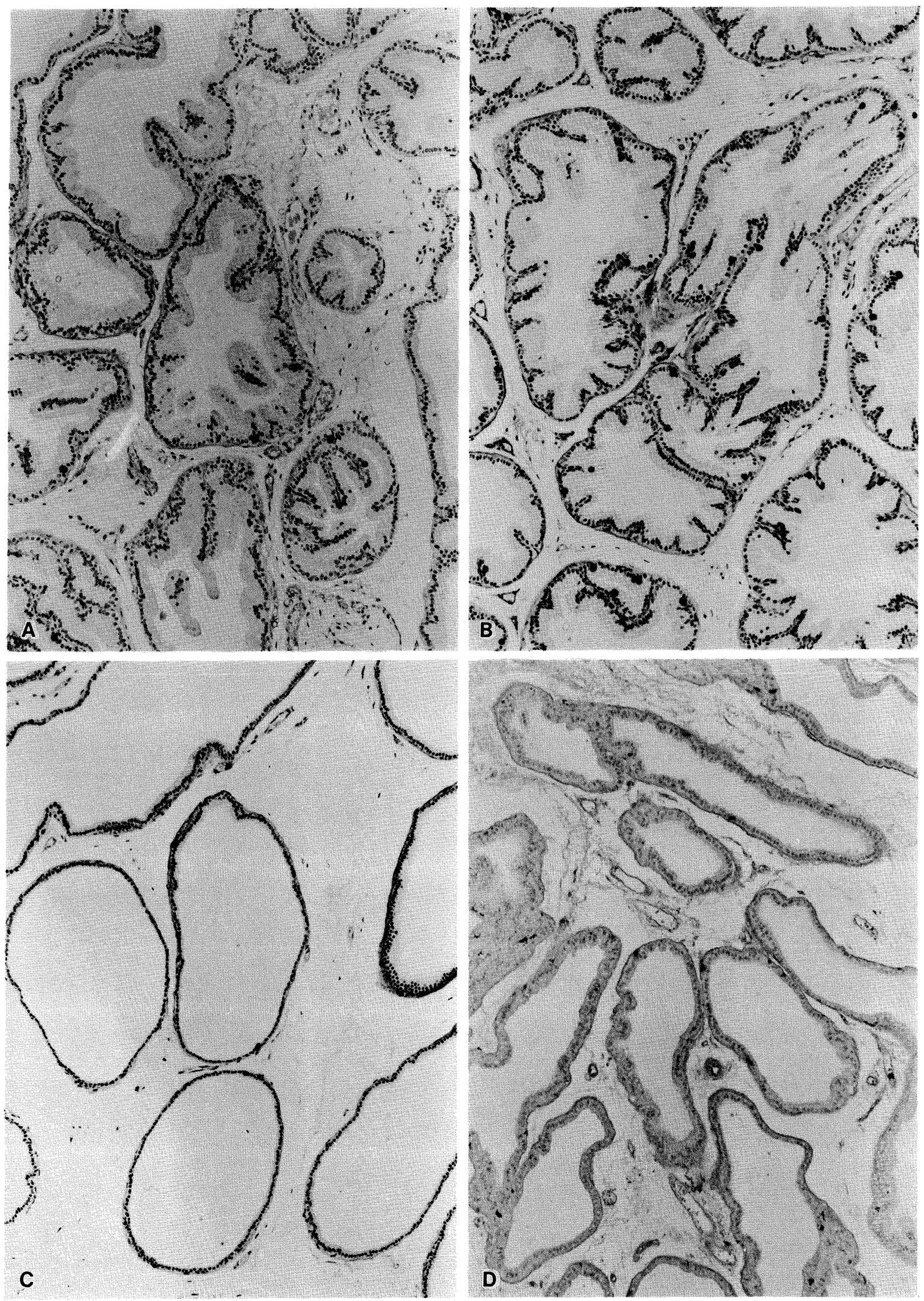

Fig. 3 

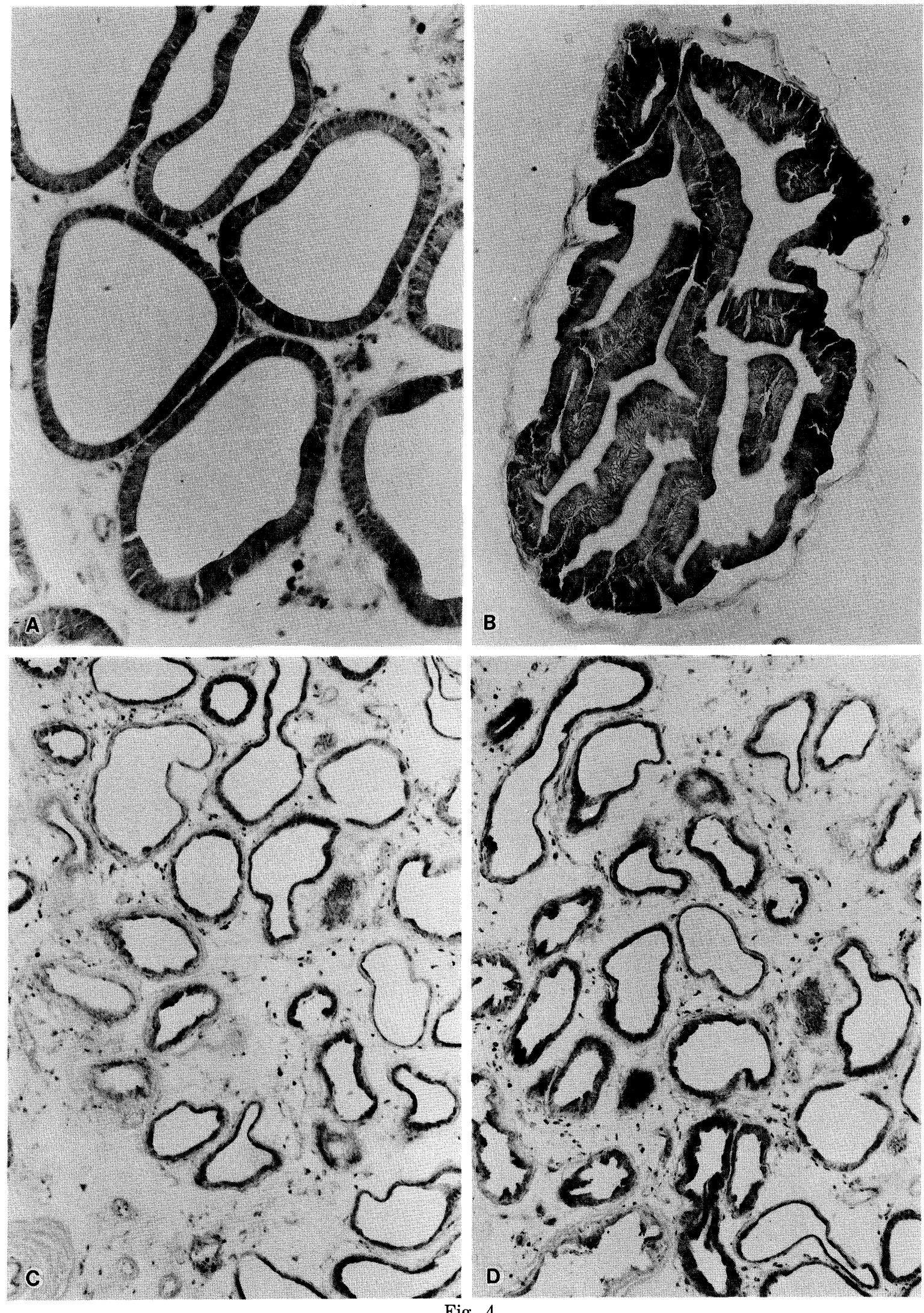

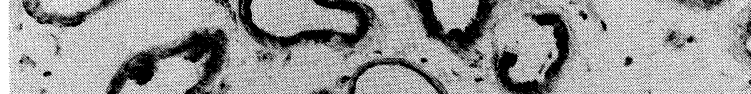
sis

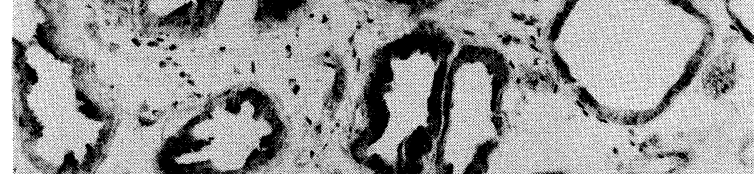
D. 30 ह Fig. 4 

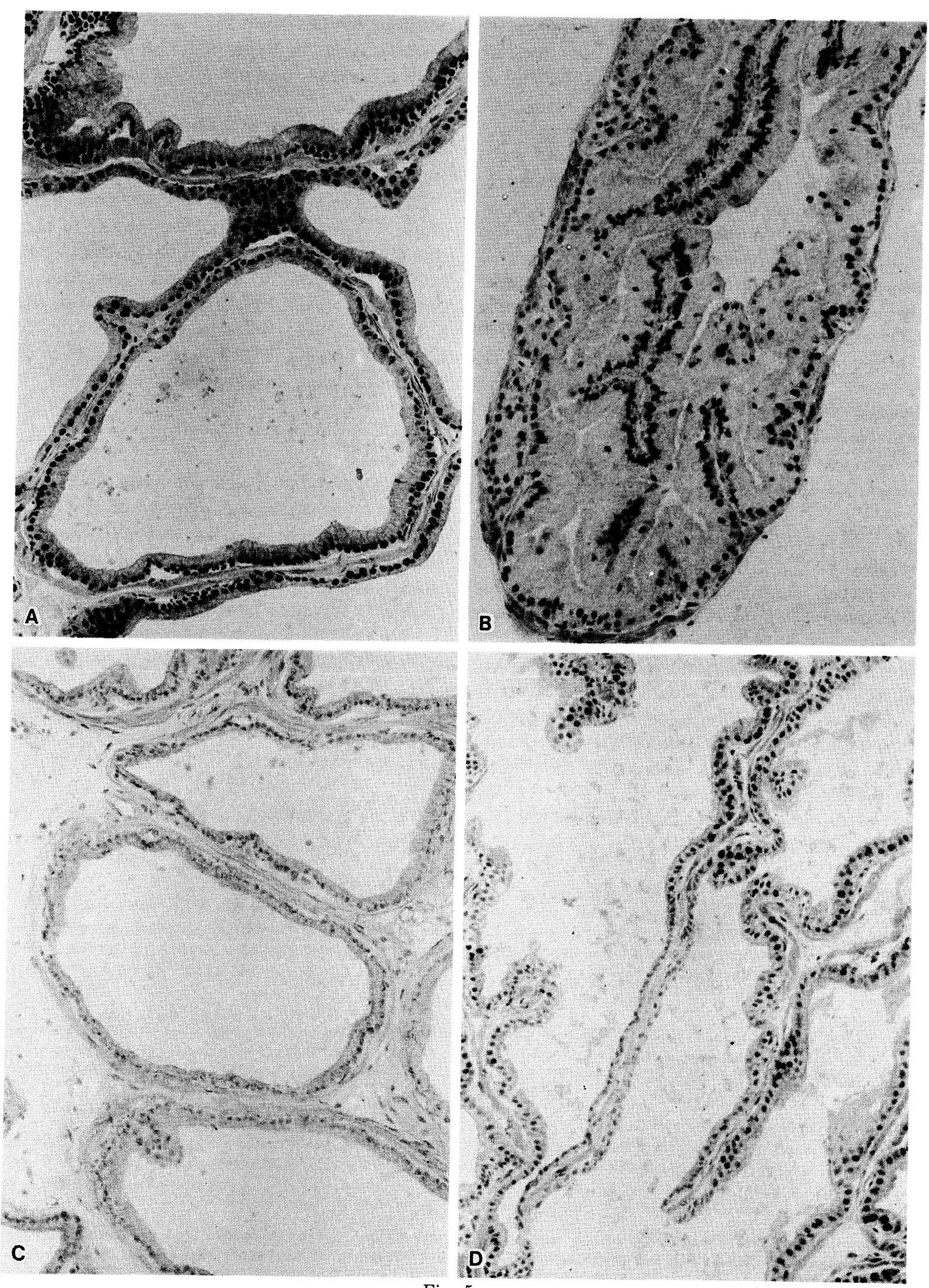

Fig. 5 
glandular epithelial cells showed a pronounced eosinophilic staining, and the nuclei were located mainly in the basal portion of the cells. The acini of the ventral prostate were relatively large with shallow papillary projections present in the acinar lumen (Fig. 2A). A few BrdU-positive nuclei were observed in the glandular epithelium (Table 1 , Fig. 3A). Immunohistochemical localization of GSH-PO was predominantly observed in the glandular epithelial cells (Fig. 4A). No reaction products were seen in the interstitial tissues. The control serum (normal rabbit serum) was negative for immunohistochemical localization of GSH-PO in the rat ventral prostate (data not shown). AR was localized predominantly in the nuclei of the epithelial cells but not in cytoplasm (Fig. 5A). No immunostaining was observed in the nuclei when the sections were incubated with preimmune serum (data not shown).

\section{Group 2 (Castration + Testosterone $+E_{2}$ )}

The glandular epithelial cells were hypertrophic and showed an increased number of papillary projections extending into the acini (Fig. 2B). The histological features of glandular hyperplasia were evident in this group. The number of BrdUpositive nuclei was greatly increased compared with the intact controls (Table 1, Fig. 3B). Furthermore, this value was statistically significant. Immunohistochemical localization of GSH-PO was seen in hyperplastic glandular epithelial cells (Fig. 4B). The intensity of GSH-PO staining was stron- ger than that of Group 1. In addition, the prostate epithelial cells in hyperplasia showed uniformly intense nuclear immunostaining for AR (Fig. 5B).

Group 3 (Castration + Testosterone $+E_{2}+T Z P$ 4238)

Glandular atrophy was major. The epithelial lining was markedly atrophied and reduced to a thin layer (Fig. 2C). The number of BrdU-positive nuclei was greatly decreased compared with Group 2 (Table 1, Fig. 3C). This value was similar to that for Group 1. Furthermore, the intensity of GSH-PO staining (Fig. 4C) and the nuclear staining of AR were markedly decreased (Fig. 5C).

Group 4 (Castration + Testosterone $\left.+E_{2}+C M A\right)$

The glandular epithelial cells had become atrophic. However, the severity of the prostatic glandular atrophy was less marked than that in Group 3 (Fig. 2D). The number of BrdU-positive nuclei was decreased compared with Group 2 (Table 1, Fig. 3D). This value was similar to that for Group 1. In addition, the intensity of GSH-PO staining (Fig. 4D) and the nuclear staining of $\mathrm{AR}$ were decreased (Fig. 5D).

\section{Discussion}

In the present study, glandular hyperplasia of the prostate was seen in castrated rats after

Fig. 2. A: Prostate of intact rat. B: Prostate of castrated rat following treatment with combined testosterone and $\mathbf{E}_{2}$. Glandular hyperplasia is clearly observed. C: Prostate of castrated rat after treatment with testosterone plus $\mathrm{E}_{2}$ plus TZP-4238. The glandular epithelium is markedly atrophic. D: Prostate of castrated rat after treatment with testosterone plus $\mathrm{E}_{2}$ plus CMA. The glandular atrophy is less severe than that induced by TZP-4238. HE stain, $\times$ $100(\mathrm{~A}, \mathrm{C}, \mathrm{D}), \times 200(\mathrm{~B})$.

Fig. 3. A: Prostate of intact rat. B: Prostate of castrated rat following treatment with combined testosterone and $\mathrm{E}_{2}$. BrdU-positive cells are markedly increased. C and D: Prostate of castrated rat after treatment with testosterone plus $\mathrm{E}_{2}$ plus TZP-4238 (C) or CMA (D). BrdU-positive cells are markedly decreased. Peroxidase-labeled antibody method. $\times 100($ A-D).

Fig. 4. A: Prostate of intact rat. GSH-PO is predominantly observed in the glandular epithelial cells. B: Prostate of castrated rat following treatment with combined testosterone and $\mathrm{E}_{2}$. In hyperplastic glandular epithelial cells, the intensity of GSH-PO staining is increased. C and D: Prostate of castrated rat after treatment with testosterone plus $\mathrm{E}_{2}$ plus TZP-4238 (C) or CMA (D). In atrophic glandular epithelium, GSH-PO staining is weaker than that of A or B. Peroxidase-labeled antibody method, $\times 200(\mathrm{~A}, \mathrm{~B}), \times 100(\mathrm{C}, \mathrm{D})$.

Fig. 5. A: Prostate of intact rat. AR is predominantly observed in the nuclei of the epithelial cells. B: Prostate of castrated rat following treatment with combined testosterone and $\mathrm{E}_{2}$. Intense nuclear immunostaining for $\mathrm{AR}$ is noted. $\mathrm{C}$ and D: Prostate of castrated rat after treatment with testosterone plus $E_{2}$ plus TZP-4238 (C) or CMA (D). The nuclear staining of AR was markedly decreased. Peroxidase-labeled antibody method, $\times 200$. 
treatment with testosterone in combination with $\mathrm{E}_{2}$. The histological appearance of the prostates in the animals that had been treated with $5 \alpha$ androstane- $3 \alpha, 17 \beta$-diol plus $\mathrm{E}_{2}$, or in castrated animals, resembled that of glandular hyperplasia $[1,11]$.

It is known that $\mathrm{E}_{2}$ alone will induce glandular atrophy of the prostate in normal and castrated animals $[5,12]$. The suppressive effects of $E_{2}$ on the male genital organs have been attributed not only to gonadotropin suppression but also to the direct effect of $\mathrm{E}_{2}$ on the gonads and their accessories [12-14]. On the contrary, it is a well documented fact that $E_{2}$ exerts a synergistic effect with androgen in promoting prostatic growth in the castrated dog [4], a fact of considerable importance in understanding the pathogenesis of prostatic hyperplasia. In fact, the stimulatory effects of testosterone were strongly potentiated by the addition of $\mathrm{E}_{2}$, resulting in the highest BrdU-positive cell ratio [15]. Therefore, glandular hyperplasia was thought to be the main feature of the rat prostatic hyperplasia occurring experimentally as a result of treatment with steroid hormones.

Combined treatment with TZP-4238 or CMA as steroidal anti-androgens produced a striking decrease of prostatic weight. In fact, the average prostatic weight following treatment with TZP$4238(8 \mathrm{mg} / \mathrm{kg})$ or CMA $(20 \mathrm{mg} / \mathrm{kg})$ were similar to those of the intact control. Furthermore, the dose of TZP-4238 required to inhibit the development of glandular hyperplasia in castrated steroidinduced rats was less than that of CMA. In addition, the histological features of glandular atrophy induced in the prostate by TZP-4238 were similar to those induced by CMA and we found that the number of BrdU-positive cells in the glandular epithelial cells was greatly decreased. These results suggest that TZP-4238 is more potent than CMA in preventing steroid-induced rat prostatic hyperplasia. This finding is in good agreement with the previous report [1].

Previously we demonstrated that the intensity of GSH-PO staining in the glandular epithelial cells of the prostate was decreased by castration and it was clearly recovered by testosteroneadministration to the castrated rats $[16,17]$. We therefore postulated that prostatic GSH-PO may be testosterone dependent [17]. In the present study, we found that the intensity of GSH-PO staining in the glandular epithelial cells of the prostate was remarkably increased after treatment with testosterone plus $\mathrm{E}_{2}$ to the castrated rats, and it was remarkably decreased after combined treatment with TZP-4238 or CMA. It is generally accepted that CMA inhibits the uptake of testosterone in the prostate and is selectively incorporated into prostate cells, inhibiting the binding of the cytosol $5 \alpha$-dihydrotestosterone-receptor [18]. On the basis of our observations and these facts, the uptake of testosterone and/or its androgenic effect on the prostate may be suppressed by TZP-4238. A rabbit polyclonal antibody referred to as $\mathrm{NH} 27$ was raised against human AR [10]. The specificity of the antibody in the immunohistochemical reaction was demonstrated by treating adjacent tissue sections with preimmune IgG. Positive staining for the antibody appeared in nuclei but not in cytoplasm from all the tissues examined (prostate, seminal vesicle, epididymis, testis, adrenal gland, kidney etc.) except for the spleen which showed no staining of the antibody [19]. In addition, immunodetectable AR rapidly declined 2 days after castration and returned to intact levels of staining intensity after testosterone-administration to the castrated rats [19]. This finding is in agreement with results of previous work on the prostate [20-22]. Therefore, NH27 was employed for the immunohistochemical localization of the rat AR. In the present study, nuclear immunostaining of AR was remarkably decreased after combined treatment with TZP-4238 or CMA. As the mechanism by which TZP-4238 produces atrophy of the prostatic glandular epithelium, Takezawa $e t$ al. [23] reported that TZP-4238 inhibited prostatic growth through 1) inhibition of the androgen receptor, 2) a decrease in nuclear androgen receptors and 3 ) a decrease in $3 \alpha$-hydroxy steroid oxyreductase activity to prevent a metabolic shift to dihydrotestosterone accumulation. The results of this study indicated that TZP-4238 binds to the rat prostatic androgen receptor and that oral administration caused regression of the hyperplastic prostatic weight. Therefore, TZP-4238 is considered to be a steroidal androgen receptor antagonist.

It is concluded that TZP-4238 is a potent steroidal androgen receptor antagonist for the preventing of rat prostatic growth in the steroidinduced prostatic hyperplasia model. 


\section{References}

1. Murakoshi M, Inada R, Makino M, Suzuki M, Mieda M, Honma S, Yamanaka H (1990) Effect of anti-androgen (TZP-4238) on steroid-induced canine prostatic hyperplasia. Light and electron microscopic investigations. Acta Pathol Jpn 40: 871879.

2. DeKlerk DP, Coffey DS, Ewing LL, McDermott IR, Reiner WG, Robinson CH, Scott WW, Strandberg JD, Talalay P, Walsh PC (1979) Comparison of spontaneous and experimentally induced canine prostatic hyperplasia. J Clin Invest 64: 842-849.

3. Tunn U, Serge T, Schenck B, Neumann F (1980) Effects of cyproterone acetate on experimentally induced canine prostatic hyperplasia. A morphological and histochemical study. Urol int 35: 125-140.

4. Wilson JD (1980) The pathogenesis of benign prostatic hyperplasia. Am J Med 68: 745-756.

5. Bartsch G, Bruengger A, De Klerk DP, Coffey DS, Rohr HP (1987) Light microscopic stereologic analysis of spontaneous and steroid-induced canine prostatic hyperplasia. J Urol 137: 552-558.

6. Graham RC, Karnovsky MJ (1966) The early stage of absorption of injected horseradish peroxidase in the proximal tubules of mouse kidney. J Histochem Cytochem 14: 291-302.

7. McLean IW, Nakane PK (1974) Periodate-lysineparaformaldehyde fixative. A new fixative for immunoelectron microscopy. J Histochem Cytochem 22: 1077-1083.

8. Nakane PK (1975) Recent progress in the peroxidase-labeled antibody method. Ann NY Acad Sci 234: 203-211.

9. Zamboni L, DeMartino C (1967) Buffered picrinic acid-formaldehyde. A new rapid fixation for electron microscopy. J Cell Biol 35: 148A.

10. Mizokami A, Masai M, Shimazaki J, Sugita A (1992) Production of polyclonal antibody against human androgen receptor and immunohistochemical study of human androgen receptor in prostatic tissues. Jpn J Urol 83: 1801-1807 (In Japanese with English abstract).

11. Walsh PC, Wilson JD (1976) The induction of prostatic hypertrophy in the dog with androstanediol. J Clin Invest 57: 1093-1097.

12. Attia MA, Zayed I (1989) Thirteen-weeks subcutaneous treated with high dose of natural sex hormones in rats. With special reference to their effect on the pituitary-gonadal axis. Dtsch tieraztt Wschr 96: 438-445.

13. Ciaccio LA, Joseph AA, Kinch FA (1978) Direct inhibition of testicular function in rats by oestradiol and progesterone. J Steroid Biochem 9: 12571259.

14. Tcholkian RK, Chowdhury M, Chowdhury AK (1978) Recovery of testicular and pituitary functions in adult male rats after cessation of short and long term oestradiol treatment. Biol Reprod 19: $431-438$.

15. Murakoshi $\mathbf{M}$, Tagawa $\mathbf{M}$, Inada $\mathbf{R}$, Suzuki $\mathbf{M}$ (1992) Effects of testosterone, and testosterone plus estrogen, in the castrated rat ventral prostate. Tokai J Exp Clin Med 17: 133-137.

16. Murakoshi M, Suzuki M, Watanabe K (1988) Immunocytochemical localization of glutathioneperoxidase in the rat prostate. Acta Histochem Cytochem 21: 283-289.

17. Murakoshi M, Suzuki M, Watanabe K (1988) Alteration of glutathione-peroxidase (GSH-PO) in rat ventral prostate. Effect of castration and testosterone administration. Acta Histochem Cytochem 21: 283-289.

18. Ito Y, Kurosawa I, Yamanaka H, Koya A, Imai K, Kosaku N, Shida K (1977) The mechanism of antiandrogenic action of chlormadinone acetate. Hinyokika Kiyo 68: 537-552 (In Japanese with English abstract).

19. Murakoshi $M$, Inada $R$, Tagawa $M$, Suzuki $M$, Mizokami A, Watanabe K (1993) Histopathological and immunohistochemical studies in the rat ventral prostate. J Toxicol Pathol (In Press).

20. Tann J, Joseph DR, Quarmby VE, Lubahn DB, Sar M, French F, Wilson EM (1988) The rat androgen receptor. Primary structure, autoregulation of its messenger ribonucleic acid and immunocytochemical localization of the receptor protein. $\mathrm{Mol}$ Endocrinol 12: 1276-1285.

21. Masai M, Sumiya H, Akimoto S, Yatani R, Chang C, Liao S, Shimazaki J (1990) Immunohistochemical study of androgen receptor in benign hyperplastic and cancerous human prostates. Prostate 17: 293-300.

22. Sar M, Lubahn DB, French FS, Wilson EM (1990) Immunohistochemical localization of the androgen receptor in rat and human tissues. Endocrinology 127: 3180-3186.

23. Takezawa Y, Fukabori Y, Yamanaka H, Mieda M, Honma S, Kushitani M, Hamataki N. The effect of antiandrogens (TZP-4238, chlormadinone acetate) on hormone induced canine prostatic hyperplasia. Prostate (submitted). 